\title{
PAISAJES CINEMATOGRÁFICOS COMO METÁFORAS DE LAS EMOCIONES. Análisis de los modos de representación fílmica y espacialidad en Her de Spike Jonze.
}

\author{
Maximiliano Maza Pérez* \\ Frida Anais Godínez Garza** \\ DOI: https://doi.org/10.33571/revistaluciernaga.v11n21a2
}

\section{Resumen}

A partir de la identificación de los elementos de la puesta en escena y la integración de las características de los espacios representados en la película Her (Spike Jonze, 2013), se analizan las funciones que cumplen los paisajes cinematográficos de dicho filme y se explica su espacialidad, o conjunto de significados expresados a través de los espacios en los que se lleva a cabo la acción dramática. Se concluye que la mayoría de los espacios analizados funcionan, en mayor o menor grado, como metáforas de las emociones experimentadas por los personajes que, en ocasiones, no se atreven a expresar. Así mismo, destaca la representación del espacio urbano abierto como una utopía insatisfactoria y, en contraste, la de algunos espacios cerrados y la del espacio virtual que funcionan como heterotopías o contraemplazamientos de otros espacios significativos, reales o ficticios.

Palabras clave: representación fílmica; cine; espacio cinematográfico; geografía cinematográfica; puesta en escena; paisaje cinematográfico; Her; Jonze.

Recibido. Junio 12, 2019

Aceptado. Junio 25, 2019

*Doctor en Estudios Humanísticos por el Instituto Tecnológico y de Estudios Superiores de Monterrey y profesor asociado en la misma institución.

Orcid: https://orcid.org/0000-0002-0047-8915; e-mail: mmaza@tec.mx

**Doctora en Estudios Humanísticos por el Instituto Tecnológico y de Estudios Superiores de Monterrey y profesora de cátedra de la misma institución.

Orcid: https://orcid.org/0000-0002-5528-4659; e-mail: frida.gogar@tec.mx 


\section{CINEMATIC LANDSCAPES AS METAPHORS FOR EMOTIONS. Analysis of the modes of filmic representation and spatiality in Her by Spike Jonze.}

Maximiliano Maza Pérez*

Frida Anais Godínez Garza**

DOI: https://doi.org/10.33571/revistaluciernaga.v11n21a2

\section{Summary}

Starting from identifying the elements of the mise-en-scène and the characteristic integration of the spaces portrayed in the film Her (Spike Jonze, 2013), the functions pictured by the cinematographic landscapes of the film are analyzed, as well as, it is explained its spatiality, or set of meanings expressed through the spaces in which the dramatic action takes place. It is concluded that most of the analyzed spaces behave, to a greater or lesser degree, as metaphors of the emotions experienced by the characters which they do not dare to express in certain moments. By this way, the representation of the open urban space stands out as an unsatisfactory utopia and, in contrast of some indoor spaces and or virtual environments that work as heterotopies or counter-sites of other significant, real or fictitious sites.

Key words: film representation; film; cinematic space; cinematic geography; mise-en-scène; cinematic landscape; Her; Jonze.

Received. June 12, $2019 \quad$ Accepted. June 25, 2019

*Doctor en Estudios Humanísticos por el Instituto Tecnológico y de Estudios Superiores de Monterrey y profesor asociado en la misma institución.

Orcid: https://orcid.org/0000-0002-0047-8915; e-mail: mmaza@tec.mx

**Doctora en Estudios Humanísticos por el Instituto Tecnológico y de Estudios Superiores de Monterrey y profesora de cátedra de la misma institución.

Orcid: https://orcid.org/0000-0002-5528-4659; e-mail: frida.gogar@tec.mx 


\section{PAISAGENS CINEMATOGRÁFICAS COMO METÁFORAS PARA AS EMOÇÕES. Análise dos modos de representação fílmica e espacialidade em Her por Spike Jonze.}

Maximiliano Maza Pérez*

Frida Anais Godínez Garza**

DOI: https://doi.org/10.33571/revistaluciernaga.v11n21a2

\section{Resumo}

A partir da identificação dos elementos da encenação e da integração das características dos espaços representados no filme Her (Spike Jonze, 2013), são analisadas as funções das paisagens cinematográficas e explicada a sua espacialidade, ou conjunto de significados expressos através dos espaços em que se desenrola a ação dramática. Conclui-se que a maioria dos espaços analisados funcionam, em maior ou menor grau, como metáforas das emoções vividas pelos personagens, que por vezes não ousam expressar. Da mesma forma, destaca-se a representação do espaço urbano aberto como uma utopia insatisfatória e, em contraste, a de alguns espaços fechados e a do espaço virtual que funcionam como heterotopias ou contra-emissões de outros espaços significativos, reais ou fictícios.

Palavras-chave: representação fílmica; cinema; espaço cinematográfico; geografia cinematográfica; encenação; paisagem cinematográfica; Ela; Jonze.

Recebido. Junho 12, 2019

Aceitado. Junho 25, 2019

*Doctor en Estudios Humanísticos por el Instituto Tecnológico y de Estudios Superiores de Monterrey y profesor asociado en la misma institución.

Orcid: https://orcid.org/0000-0002-0047-8915; e-mail: mmaza@tec.mx

**Doctora en Estudios Humanísticos por el Instituto Tecnológico y de Estudios Superiores de Monterrey y profesora de cátedra de la misma institución.

Orcid: https://orcid.org/0000-0002-5528-4659; e-mail: frida.gogar@tec.mx 


\section{Introducción}

Ubicada en los géneros de ciencia ficción, drama y romance, Her (2013) es el cuarto largometraje fílmico dirigido por el director estadounidense Spike Jonze (IMDb, 1990-2019); sin embargo, el guion es su opera prima como escritor en solitario. Anteriormente, Jonze había compartido el crédito de guionista con Charlie Kaufman en Being John Malkovich (1999) y Adaptation (2002), así como con Dave Eggers, quien colaboró en la adaptación cinematográfica dirigida por Jonze del libro infantil de Maurice Sendak, Where the Wild Things Are (1963) en 2009 (Barlow, 2014).

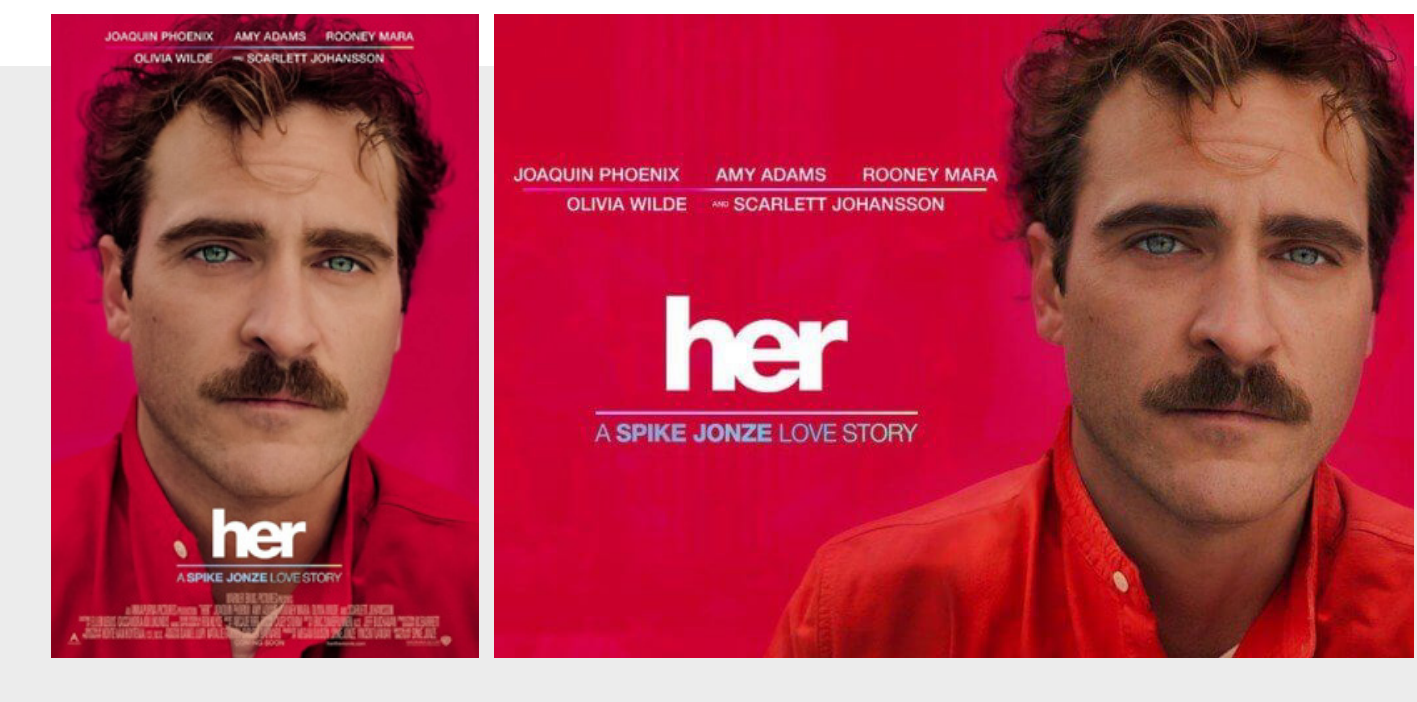

Imagen: https://bit.ly/2WtmFaT

Her se presentó el día 13 de octubre de 2013 en el New York Film Festival para cerrar el evento y se estrenó en algunas salas de cine de manera limitada durante el mes de diciembre, para finalmente proyectarse mundialmente a partir del 10 de enero del 2014, esto, con el fin de cumplir los requerimientos de los diversos festivales cinematográficos internacionales en donde fue presentada (Mc Nary, 2013). El filme de Jonze contó con 180 nominaciones y 83 premios, entre los cuales obtuvo el Oscar a mejor guion original, además de recibir galardones en los Golden Globes, AFI Awards, Art Directors Guild y Austin Film Critics Association, entre otros, en categorías como mejor película, diseño de producción, música y actuación.

La historia protagonizada por Joaquin Phoenix (Theodore) y Scarlett Johansson (Samantha) se inspiró en un artículo que el guionista y director había leído más de diez años atrás, en el que se discutía la posibilidad de enviar mensajes a un sistema de inteligencia artificial, mismo que respondía al llamado; así, imaginó como sería una relación romántica entre una persona y un sistema operativo y surgió la historia de amor. Jonze (en Barlow, 2016) afirma que la película aborda distintas ideas que estuvo pensando y que le provocaron confusión sobre la manera en que vivimos y llevamos nuestras relaciones, así como la forma en que tratamos de conectarnos y fallamos. 

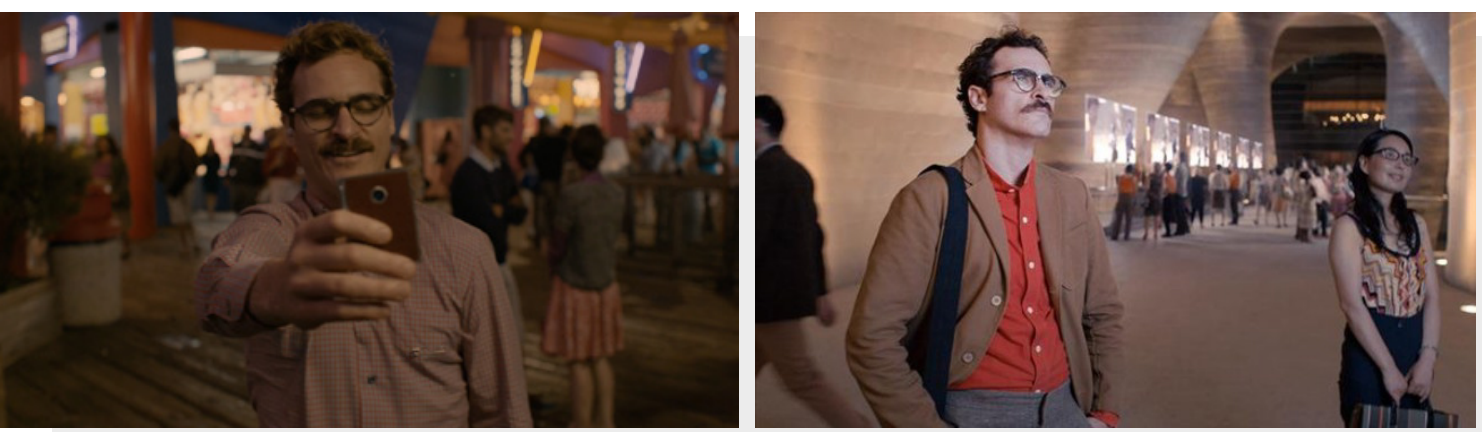

Imagen: https://bit.ly/34hjea4

El presente trabajo propone llevar a cabo el análisis descriptivo de los modos de representación fílmica del espacio en la película Her (Spike Jonze, 2013) [1]. Este proceso se desarrolla en dos fases: la primera, de naturaleza exploratoria, busca identificar los elementos de la puesta en escena en el filme, sus significados particulares, así como la manera en que se combinan para determinar las características del espacio representado en la pantalla; la segunda, de carácter dilucidador, integra dichas características bajo el concepto de paisaje cinematográfico, con el propósito de analizar sus funciones y explicar la espacialidad de la película: el conjunto de significados expresados a través de los espacios en los que se lleva a cabo la acción dramática del filme.

El análisis de la espacialidad cinematográfica constituye una manifestación del mayor interés que existe hacia el estudio de los fenómenos de carácter espacial y geográfico en el campo de los estudios culturales. Jackson (1999, p. 46) considera que "la creciente popularidad de términos (geográficos) tales como centro y periferia, fronteras y zonas fronterizas, espacios, lugares y dominios" es prueba del giro espacial experimentado por los estudios culturales desde la década de los ochenta del siglo XX. En este sentido, el surgimiento de campos transdiciplinarios como el de la geografía cinematográfica, subdisciplina de la geografía cultural que estudia los modos de representación fílmica del espacio geográfico, demuestra la importancia adquirida por la dimensión espacial en los estudios sobre la cultura.

El análisis descriptivo de los modos de representación fílmica del espacio se presenta como una forma de aproximación al estudio de la espacialidad, concepto acuñado por el geógrafo político Edward Soja a partir de la noción del sociólogo francés Henri Lefebvre de que el significado del espacio es producido socialmente. Soja (1994, p. 80) afirma que el espacio físico solo adquiere significado a través de "la traducción social, la transformación y la experiencia". Así mismo, como herramienta metodológica para explicar la espacialidad cinematográfica, el análisis descriptivo contribuye a valorar, de forma más completa, el conjunto de elementos estéticos e ideológicos que constituyen al filme como discurso. 


\section{Espacios de representación significativos en el filme Her de Spike Jonze}

En su análisis sobre las formas de conceptualizar el espacio en la cultura occidental, Michel Foucault (1999, pp. 431-432) desarrolla una historia del espacio que se origina en la Edad Media, a partir de la localización jerarquizada de las cosas en el mundo físico y fuera de este; se extiende en la época de Galileo, cuando el espacio se vuelve "infinito e infinitamente abierto"; y llega hasta nuestros días, cuando vivimos "en la época de lo simultáneo, en la época de la yuxtaposición, en la época de lo próximo y de lo lejano, de lo contiguo, de lo disperso", transformado en un conjunto de relaciones de emplazamiento. Desde esta perspectiva, existen lugares "que tienen la curiosa propiedad de estar en relación con todos los demás emplazamientos, pero de tal modo que suspenden, neutralizan o invierten el conjunto de las relaciones que, a través suyo se encuentran designadas, reflejadas o pensadas" (Foucault, 1999, p. 434).

Estos emplazamientos son de dos tipos: las utopías, o emplazamientos sin lugar real, y las heterotopías: lugares reales, que son una especie de contraemplazamiento, en los que "todos los demás emplazamientos reales que se pueden encontrar en el interior de la cultura, están a la vez representados, impugnados e invertidos" (Foucault, 1999, pp. 434-435).

Ambos tipos de emplazamientos, utópicos y heterotópicos, se revelan como espacios de representación significativos en Her, filme escrito y dirigido por Spike Jonze, que narra la historia de amor entre Theodore Twombly (Joaquin Phoenix), un retraído y sensible hombre que se gana la vida escribiendo cartas personales a nombre de otras personas, y Samantha (voz de Scarlett Johansson), un sistema operativo inteligente que tiene la capacidad de aprender y que rápidamente desarrolla una personalidad casi humana, a pesar de que solo existe en la forma de una voz femenina que emana de un dispositivo móvil. Theodore se encuentra en proceso de recuperarse del fracaso de su matrimonio con Catherine (Rooney Mara) y vive solo en un amplio departamento decorado de forma minimalista. La historia, que se desarrolla en un tiempo no especificado, a medio camino entre el presente y el futuro, se ubica en una metrópolis ultramoderna que solo existe en el plano de la ficción.

En la película, los emplazamientos utópicos se manifiestan principalmente en escenarios de la ciudad de Los Ángeles, California, que se presenta como una urbe sofisticada, cómoda y funcional, sin problemas de tráfico ni de contaminación ambiental o visual: un entorno futurista, que lejos del típico ambiente gélido de la ciudad del mañana, se intenta mostrar como cálido y acogedor. La construcción cinematográfica de la utopía se logra mediante la fusión de elementos icónicos de la multicultural ciudad californiana con los de la megalópolis china de Shanghái, otro espacio igualmente cosmopolita. Edificios, plazas y otros sitios de ambas urbes se presentan de forma coordinada, de manera que el resultado constituye, al mismo tiempo, una versión idealizada de cada una y un replanteamiento del cual emana una atmósfera distinta a la que impregna a estas ciudades en el mundo físico. Por su parte, la heterotopía es presentada a partir de ese espacio singular en el que se desarrolla el no menos insólito romance entre Theodore y Samantha: una relación que se caracteriza primordialmente por la ausencia de un espacio físico en donde encontrarse, convivir y amarse; un romance en el que desaparece la experiencia de tocar, mas no la de sentir. 
Dentro del ámbito de los estudios culturales, Barker (2000, p. 135) destaca la importancia del espacio, puesto que este constituye "el foco de la experiencia humana, de la memoria, el deseo y la identidad". Para este autor, como para Soja (1994), el espacio se construye a partir de las relaciones humanas que se generan en él. En este sentido, la ciudad representada por Jonze en Her correspondería a la idea de un espacio contenedor de emplazamientos definidos por la naturaleza de las relaciones sociales que se desarrollan en ellos. Dichos emplazamientos constituyen, de acuerdo con Barker (2000, p. 135), "construcciones discursivas que son el objetivo de identificación o inversión emocional".

\section{El análisis descriptivo como herramienta metodológica para explicar la espacialidad cinematográfica}

Como forma discursiva, la descripción ha sido estudiada a fondo por la corriente del análisis del discurso de la Escuela de Neuchâtel, la cual aborda el estudio del discurso desde la perspectiva de la lógica natural o sistema de operaciones que permite construir los esquemas mentales que se generan durante un acto comunicativo. Miéville (1986, p. 120) considera a la descripción "como una forma particular de esquematización" que se construye progresivamente a partir de la suma de aspectos singulares que van integrando una totalidad. Como herramienta de análisis fílmico, la descripción ofrece posibilidades interesantes para explicar los significados asociados a la dimensión espacial del filme, la cual con frecuencia resulta desplazada por las aproximaciones desde la narratología que consideran al espacio como uno más de los elementos del relato fílmico.

Casetti y di Chio (2007) consideran tres niveles de representación espacial en una película o producción para la televisión: la puesta en escena, el encuadre o puesta en cuadro y el montaje o puesta en serie. Para el presente caso de estudio, se seleccionó a la puesta en escena como el nivel de representación espacial a analizar. La identificación de lo que expresan y la manera en que se combinan los elementos de la puesta en escena cinematográfica permiten determinar las características del espacio representado en la pantalla y, a partir de ello, integrar el paisaje cinematográfico, cuyas funciones contribuyen a explicar la espacialidad de la película.

Como concepto que ha trascendido sus orígenes teatrales, la puesta en escena cinematográfica se puede definir como la combinación de los elementos de naturaleza visual y sonora contenidos en cada escena de un filme. Vale (2006, pp. 25-31) señala que la puesta en escena cinematográfica se construye a partir de un conjunto de elementos significativos, entre los que incluye a los personajes, el decorado, los accesorios y objetos, la iluminación y el sonido. Los personajes son el elemento esencial a partir de cuyas acciones y diálogos se desarrolla el drama. En términos espaciales, los personajes suelen constituir el centro alrededor del cual se construye la puesta en escena cinematográfica. El decorado extiende sus límites teatrales originales a cualquier tipo de ambiente o trasfondo, localizado en el mundo material o creado especialmente para la pantalla.

Los accesorios caracterizan tanto al decorado como a los personajes, mientras que los objetos [1] poseen la capacidad de incorporarse a la acción dramática. La iluminación resulta ser un elemento importante en la construcción dramática de 
la escena para comunicar no solo su temporalidad (día/noche) y localidad (interior/exterior), sino también el estilo visual y el carácter emocional del filme. Finalmente, el sonido, compuesto por el ruido ambiente y la música de fondo, puede contribuir a la descripción fílmica, aunque en ocasiones, como es el caso de la banda sonora de Her, se vincula principalmente con la expresión emocional de los personajes y constituye un refuerzo para la carga dramática de las escenas del filme.

Los elementos de la puesta en escena cinematográfica no suelen actuar de manera independiente. Vale (2006, p. 33) describe dos procesos de combinación a partir de los cuales dichos elementos se convierten en fuentes de información para el espectador de una película. Estos procesos ocurren tanto al interior de cada escena (combinación simultánea) como entre una escena y otra (combinación consecutiva).

El presente análisis se concentrará primordialmente en el primero de ambos procesos y en la manera en que la combinación simultánea de elementos de la puesta en escena permite determinar las características del espacio (Vale, 2006, p. 49) donde se lleva a cabo la acción dramática del filme: su tipo o denominación; su clase o caracterización; su propósito o función; así como su relación con los personajes y su ubicación geográfica. La determinación de las características del espacio en un análisis descriptivo se logra a través de cuatro macroperaciones: anclaje, o asignación de nombre al lugar descrito; aspectualización, o enumeración de partes, funciones o cualidades del sitio; tematización, o expansión de la descripción a características más específicas; y asimilación, o comparación con las características o cualidades de otro espacio (Adam y Petitjean, 1989, pp. 112-115, 128-133). Dichas macroperaciones descriptivas se ordenan de forma jerárquica, pero se enuncian consecutivamente.

La determinación de las características del espacio cinematográfico constituye el punto de partida para la segunda mitad del proceso de análisis descriptivo de la película Her de Spike Jonze. A partir de la valoración de estas es posible analizar la espacialidad de cada escena. Para ello, el conjunto de características del espacio cinematográfico se integra en una unidad de análisis denominada paisaje cinematográfico (Lukinbeal, 2005; Escher, 2006) cuyas funciones están establecidas a partir de la taxonomía propuesta por Higson $(1984,1987)$ para el espacio en un filme. Así, un paisaje cinematográfico puede cumplir cuatro funciones: dramática, histórica, metafórica y espectacular. En primera instancia, el paisaje cinematográfico constituye un espacio para el desarrollo del drama; en segundo lugar, permite autentificar la ficción al presentarse como un lugar históricamente específico; una tercera función es la de servir como metáfora de las emociones y pensamientos de los personajes o de grupos sociales más amplios; finalmente, a través de la función espectacular, el paisaje se ofrece a la mirada como un espectáculo que permite valorar los aspectos estéticos e ideológicos del discurso fílmico al "establecer una relación afectiva entre los personajes, los espectadores y el espacio (...) que contribuye a redefinir los significados adheridos al paisaje que es representado en la pantalla" (Autor/a, 2014, p. 112).

En el presente estudio se incorporaron tanto la revisión del producto fílmico terminado como el análisis de las descripciones escritas por Spike Jonze en el guion cinematográfico, además de otros documentos relacionados con la película, como artículos y entrevistas con el personal técnico y artístico involucrado en su realización. La presentación de resultados del análisis descriptivo que se desarrolla a continuación se divide en tres grandes apartados, correspondientes a cada uno de los tres espacios que aparecen con mayor 
frecuencia en la película: la oficina de Theodore, su departamento y el entorno urbano y suburbano que lo rodean. Debido a las delimitaciones requeridas para la presentación de este trabajo, se optó por exponer información que describiera las características generales de los tres espacios ya definidos, seleccionando además escenas clave de cada lugar, mostrando así su relación con los protagonistas en el inicio y fin de la relación amorosa entre Theodore y Samantha.

\section{Puesta en escena y paisaje cinematográfico en $\mathrm{Her}$}

\section{Interior - Oficina de Theodore}

El primer anclaje y uno de los más importantes paisajes cinematográficos de Her lo constituye la oficina donde trabaja Theodore. Es una oficina ultramoderna cuyo primer propósito y función dramática es servir como un espacio de trabajo, donde el protagonista redacta cartas escritas "a mano" por computadora, en una suerte de versión posmoderna del escritorio público que, en sí mismo, constituye una heterotopía del espacio privado del escritorio.

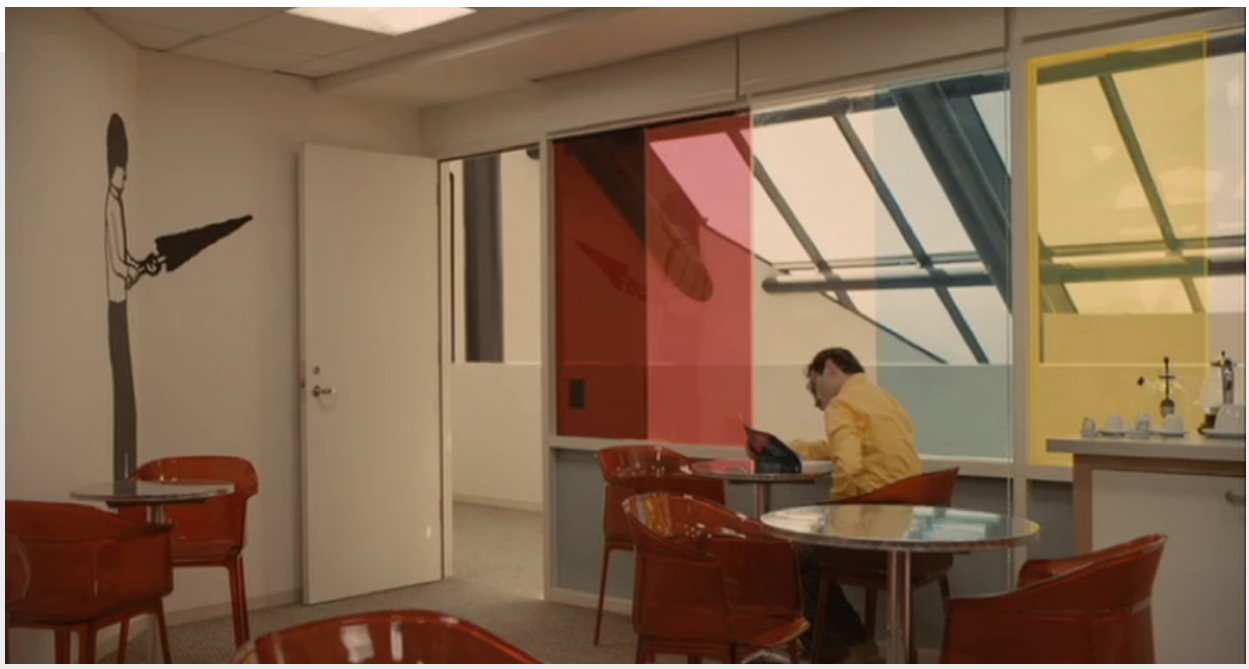

El decorado y los accesorios que caracterizan la puesta en escena de la oficina de Theodore la aspectualizan como un espacio semipúblico de vocación laboral. Dichos elementos se encuentran en constante tensión y replantean la clase y propósito del espacio, así como su relación con el protagonista de la cinta. En una primera impresión, la oficina se revela como un sitio austero, semiautomatizado e impersonal, donde apenas se insinúa la cálida personalidad de Theodore. Conforme se revelan los detalles del decorado y los accesorios y el espacio se tematiza, se observan vestigios de intervención humana que suavizan la angulosidad de las formas predominantes y hacen más acogedor el ambiente. De esta manera, la oficina se revela ante los ojos del espectador como un espacio en el que destacan las líneas y ángulos rectos, pero tematizado con enormes vinilos de colores primarios en tonos cálidos que cubren las ventanas y dibujos que decoran las mamparas blancas que parecen haber sido hechos a mano con plumón negro. 
El efecto contradictorio provocado por la tematización de la oficina es importante puesto que contribuye a subrayar los aspectos discordantes de la personalidad de Theodore. En este sentido, la segunda función del paisaje cinematográfico de la oficina de Her es actuar como metáfora de la psique del protagonista, un hombre tímido y reservado, que se abrocha hasta el último botón de la camisa, pero que es capaz de expresar emociones profundas y una gran sensibilidad, lo que queda de manifiesto a través de las cartas que escribe a nombre de sus clientes.

Destaca la manera en que el decorado, los accesorios y la iluminación de la oficina se modifican conforme avanza la trama y las emociones del protagonista se intensifican. Inicialmente, la iluminación principal del lugar apenas si cae sobre el rostro de Theodore, el cual aparece en penumbras o ligeramente iluminado por la pantalla de su computadora o la luz de la fotocopiadora. En contraste, las caras de sus compañeros de trabajo se perciben claramente iluminadas. Una vez que se establece la relación entre Theodore y Samantha, el lugar de trabajo luce más acogedor, la iluminación más brillante y los colores más vivos, hasta el grado de saturarse de rojos, lo cual enfatiza el grado de enamoramiento de Theodore.

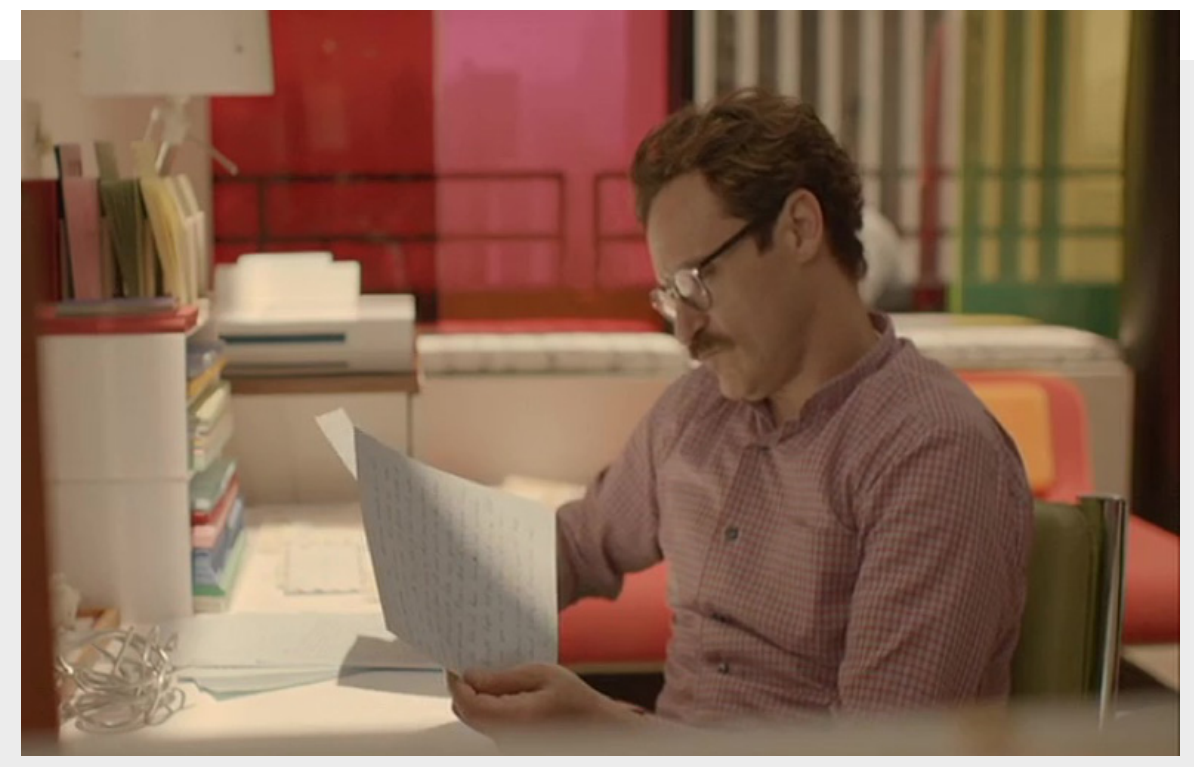

Conforme avanza la acción del filme, el paisaje cinematográfico de la oficina refleja los altibajos del romance entre Theodore y Samantha, hasta llegar al inexorable final de su relación. Cuando Samantha desaparece debido a que actualiza su versión de ella misma como sistema operativo computacional, la oficina se convierte en un espacio de tránsito que se vacía ante su ausencia. Más adelante, cuando Theodore se entera de que Samantha sostiene múltiples romances simultáneos con otros sistemas iguales a ella, el decorado de la oficina se vislumbra austero, con los colores apagados. Hacia el final de la película, por primera vez en ese espacio, Theodore mira por una de las ventanas el panorama de la ciudad que se muestra envuelta en una bruma e iluminada por capas de luz de un color sepia saturado. Esa misma tarde, Theodore y Samantha se despiden para siempre. 


\section{Interior - Departamento de Theodore}

Al igual que el espacio semipúblico laboral de la oficina, el departamento de Theodore, principal emplazamiento privado de Her, cumple con la doble función de servir como espacio para el desarrollo del drama y como metáfora del estado de ánimo de su protagonista. Al igual que el paisaje cinematográfico analizado anteriormente, la función del departamento como símbolo de la transformación emocional de su habitante es más significativa que su uso como escenario del drama.

Aunque casi siempre luce vacío, como subrayando la reciente mudanza de su ocupante, el departamento no se percibe como un espacio impersonal, debido en gran medida a su caracterización sonora. El efecto contradictorio entre la aspectualización visual y sonora del espacio privado de Theodore refleja la tensión entre las características que definen al personaje como un ser solitario y, al mismo tiempo, sensible y afectuoso. El constante uso de música en las escenas que se desarrollan en el departamento le otorga al espacio privado una cualidad de calidez que contrasta con lo que comunica su austero mobiliario. Por el número de veces que aparecen en pantalla, la recámara y el salón constituyen los dos ambientes más representativos del departamento como paisaje cinematográfico.

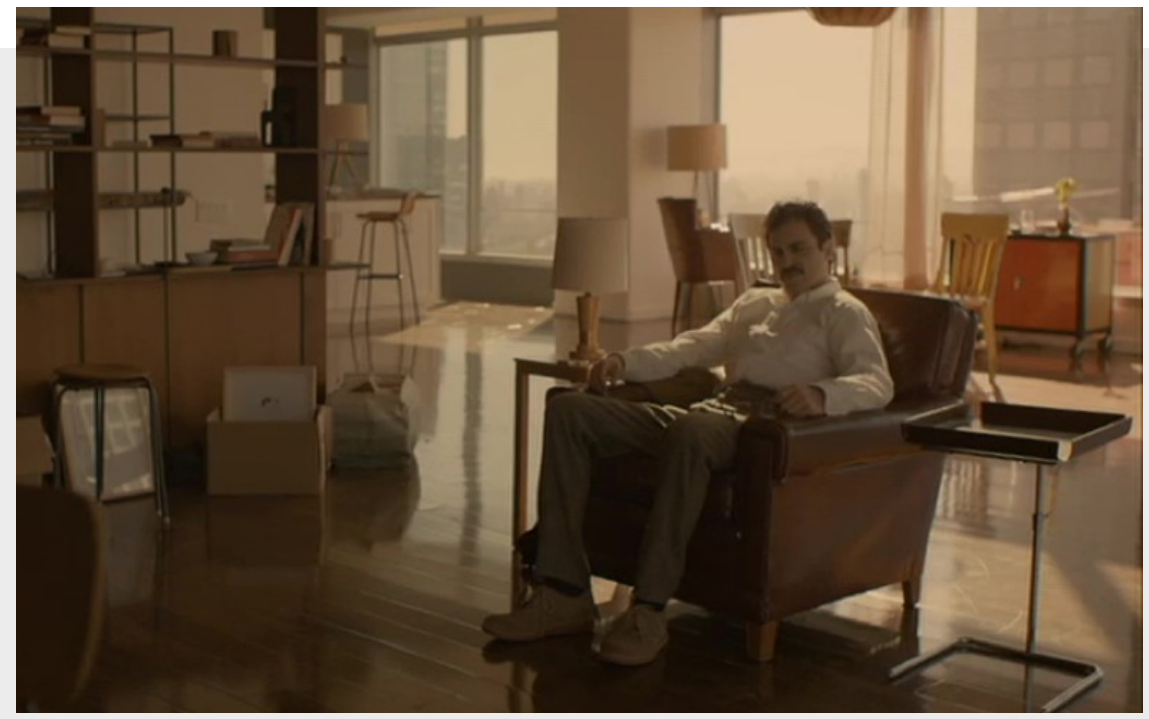

Tras adquirir el sistema operativo OS1 ("Una entidad intuitiva que te escucha, te entiende y te conoce" [2], Theodore se encuentra en el salón de su departamento, instalando el programa en su computadora personal, un artefacto de pantalla plana y sin teclado que, al igual que el resto de las que aparecen el filme, se presentan como accesorios que caracterizan una época incierta, entre el presente y el futuro. Las luces de la ciudad se asoman por el enorme ventanal, mientras que el salón aparece iluminado con luces indirectas. La iluminación principal proviene de la pantalla de la computadora y de un par de lamparitas colocadas a cada lado del aparato. Una de las lámparas emite una cálida luz rojiza, producida por efecto de la pantalla color naranja que cubre el foco. 
El mismo color se duplica en la camisa de Theodore y en la pantalla de instalación del sistema operativo. De nueva cuenta, la tematización del espacio es contradictoria: cálida por la iluminación y los colores de la camisa y la pantalla, fría por la ausencia de otro ser humano junto a Theodore.

Una vez que Theodore y Samantha entran en contacto, la cálida voz femenina "rompe el hielo" entre ambos gracias a su agudeza verbal y a un juego de inflexiones que denota matices de coqueteo y simpatía. Los parlamentos de Samantha la revelan como poseedora de una "personalidad" eficiente, divertida y empática, capaz de seleccionar su nombre de entre 180 mil y bautizarse en dos centésimas de segundo, reírse de sí misma y anticipar las necesidades de su poseedor. La imagen final de la escena resulta reveladora de la nueva relación entre ambos. Es una toma abierta que muestra a Theodore de cuerpo entero, sentado en actitud relajada; su postura corporal es la de alguien que habla con otra persona a través del teléfono o de un dispositivo semejante. La cámara se aleja lentamente y muestra el salón casi vacío y desarreglado. A partir de ese instante, el paisaje cinematográfico del departamento se transforma en el albergue de una relación que trasciende los límites físicos para insertarse en el espacio concebido (espace conçu) de Lefebvre (1991, pp. 38-39): el espacio de las ideas que, con algunas excepciones, tiende a ser expresado a través de la palabra y que configura la espacialidad dominante en cualquier sociedad.

Un par de noches más tarde, luego de que Theodore regresa de una cita fallida con una mujer, la compenetración entre él y Samantha se vuelve más profunda. En medio de la penumbra de la recámara, los personajes se confiesan sus preocupaciones: mientras que a él le inquieta la posibilidad de enfrentarse a un vacío emocional, a ella la aflige no comprender si sus sentimientos son reales o si son solo programación. La vulnerabilidad emocional de ambos, expresada a través de los diálogos y la actuación [3], se acentúa con un fondo musical muy suave. El acercamiento que se suscita entre los dos trasciende los límites de lo amistoso y se convierte en un encuentro sexual, durante el cual el espacio físico de la recámara se funde con el espacio virtual donde habita Samantha. En ese momento, la puesta en escena de la recámara se disuelve en una negrura absoluta: en la creación de un espacio hermético, que solo pertenece a ellos y que al mismo tiempo se manifiesta infinito y materialmente inexistente.

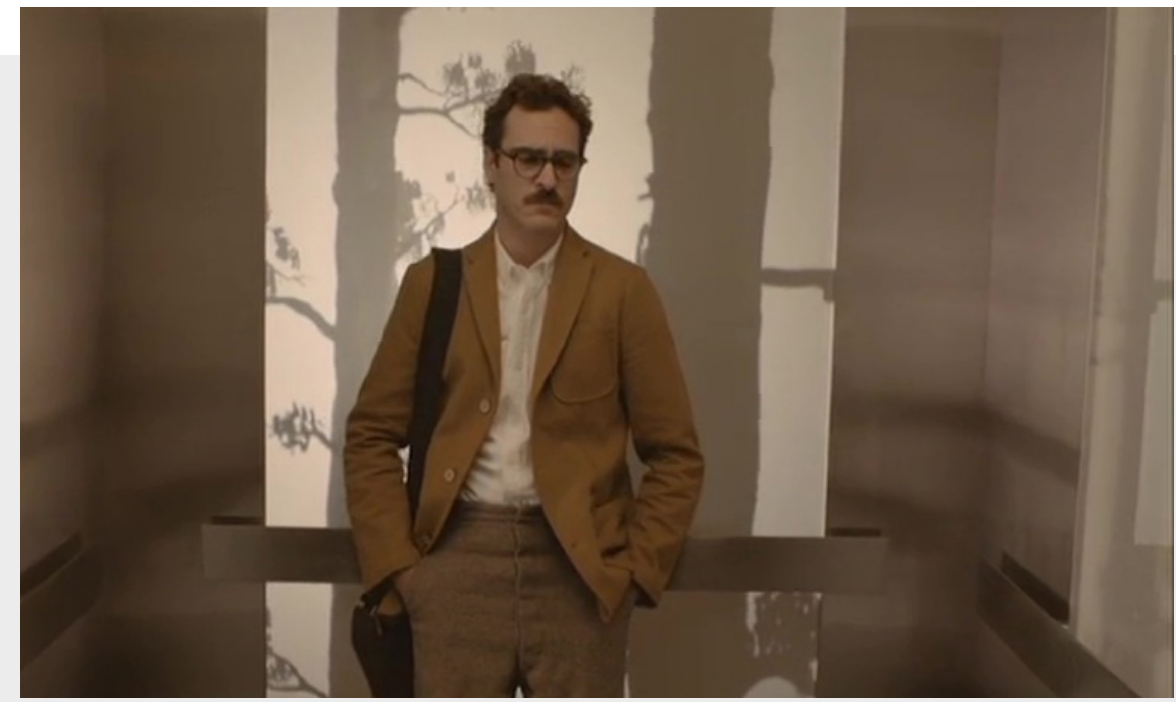


Hacia el final del filme, tras una serie de experiencias que provocan cambios en los sentimientos de ambos, Samantha le confiesa a Theodore que se ha enamorado de otras personas y sistemas operativos. La recámara vuelve a ser un espacio de representación significativo o espacio vivido (espace vécu) (Lefebvre, 1991, p. 39) de un momento trascendental de la relación, esta vez de su final. Recostado sobre la cama tendida, Theodore escucha a Samantha explicarle que se va, al igual que los demás sistemas operativos que han adquirido un nivel de conciencia superior. La luz que entra por las ventanas indica que la escena sucede por la tarde, antes de la puesta del sol. Partículas de polvo caen lentamente en la habitación mientras Samantha recurre a la macroperación descriptiva de asimilación o comparación con las características de otro espacio para explicarle a Theodore cómo se siente.

Es como si estuviera leyendo un libro, y es un libro que quiero profundamente, pero ahora lo estoy leyendo lentamente de modo que las palabras están separadas y los espacios entre las palabras son casi infinitos. Todavía te siento a ti y las palabras de nuestra historia, pero ahora me encuentro en el espacio sin fin entre las palabras. Es un lugar que no pertenece al mundo físico, es donde está todo lo demás que yo ni sabía que existía. Te quiero muchísimo, pero aquí es donde estoy ahora. Esto es quien soy ahora (Jonze, 2011, p.102). [4]

Las partículas de polvo dan paso a una fina nevada, mientras el espacio vacío de la recámara se transforma en un bosque helado y oscuro, en el que un desolado Theodore abraza, por primera y última vez, al amor de su vida.

\section{Exterior - La ciudad y sus alrededores}

Como se ha mencionado anteriormente, el paisaje cinematográfico en Her corresponde a un espacio construido a partir de aspectos geográficos y urbanísticos de las ciudades de Los Ángeles y Shanghái, además de algunas zonas de la costa de California. En las imágenes que se presentan en el filme se combinan calles, edificios, restaurantes, oficinas, estaciones de metro y departamentos de ambas ciudades, así como algunos espacios naturales en donde los personajes conviven, como playas, bosques y montañas nevadas.

La primera escena exterior muestra un decorado urbano, caracterizado a partir de elementos arquitectónicos ultramodernos, los cuales son iluminados en azules con tonos grisáceos y leves toques de color amarillo. La puesta en escena enfatiza la frialdad y desolación del panorama, apenas alumbrado por las luces de las ventanas de los edificios. La clase de lugar (lo que lo distingue de otros de su mismo tipo) corresponde en este caso a una ciudad futurista de un país económicamente desarrollado, con un ambiente limpio y ordenado, tal como fue concebida por Jonze y su diseñador de producción, K. K. Barret, quienes deseaban enfatizar la belleza visual de la arquitectura y celebrar así un futuro no lejano, en el que los espacios minimalistas proveerán de comodidad y practicidad a sus habitantes (Curbed LA: The Los Angeles Neighborhood and Real Estate Blog, 18 de diciembre de 2013). 


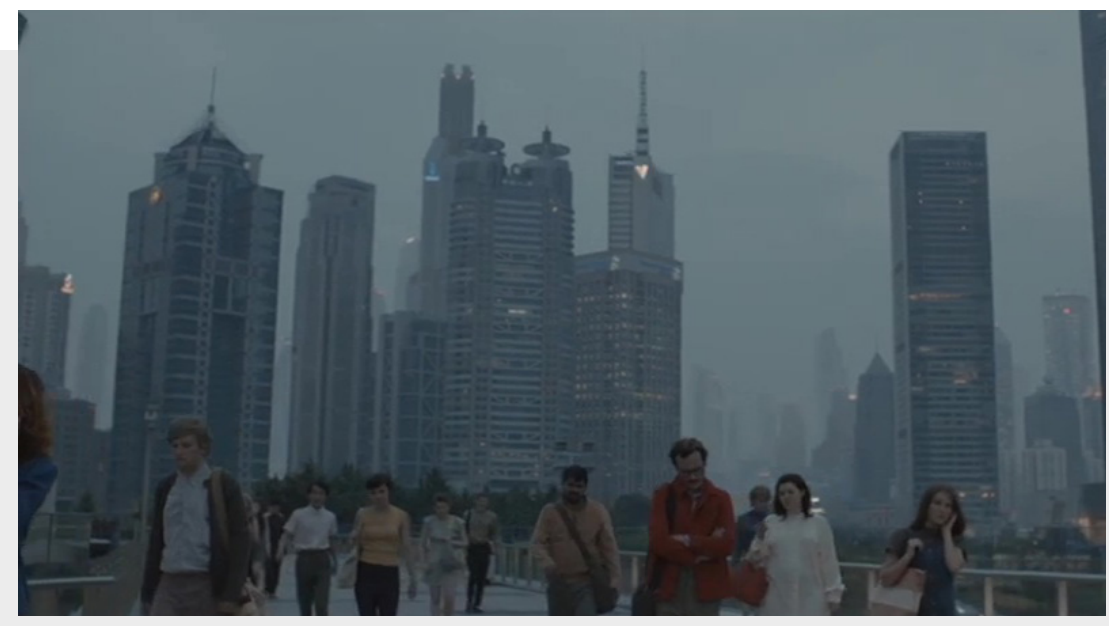

Podría suponerse que una de las funciones primordiales del paisaje cinematográfico de la ciudad en Her sería presentarla como un lugar históricamente específico; sin embargo, su localización geográfica y su consecuente anclaje es probablemente la más elusiva y contradictoria de las macroperaciones descriptivas que cumple el paisaje urbano en el filme de Spike Jonze. Si bien al comienzo de la cinta el protagonista recibe un correo electrónico con el pronóstico del clima de Los Ángeles y se hacen varias alusiones a dicha ciudad californiana, también es cierto que, en términos arquitectónicos, la ciudad donde se desarrolla la trama de Her es representada como un espacio híbrido, confeccionado a partir de la edición y los efectos visuales (Hawthorne, 18 de enero de 2014).

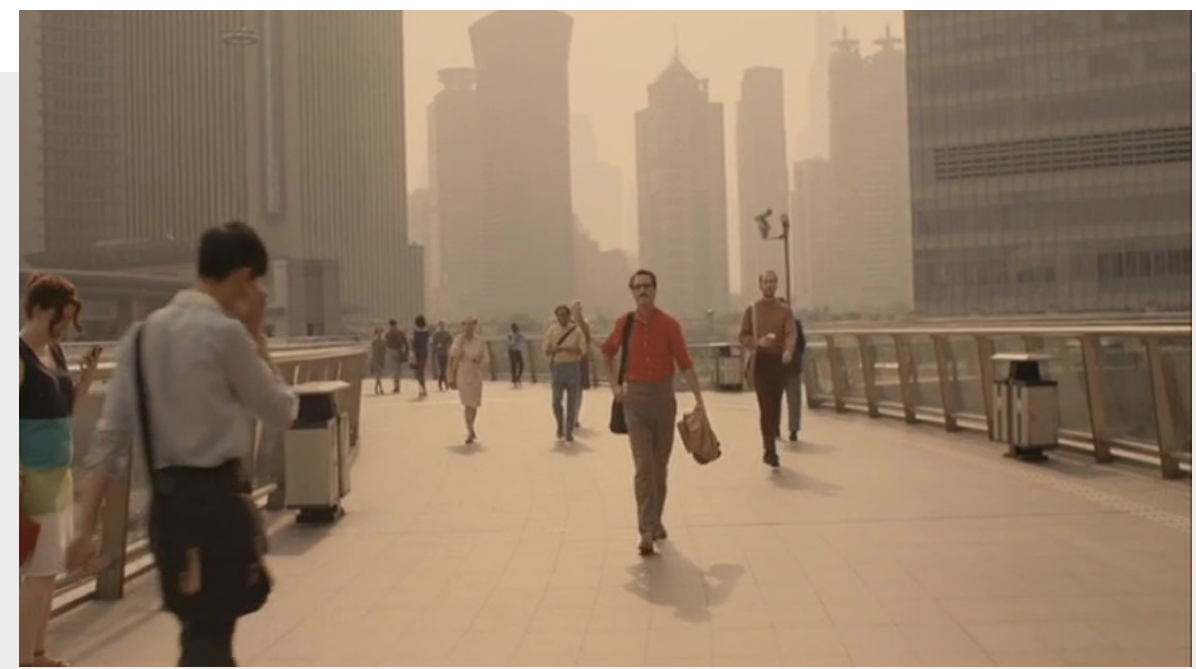

Aunado a lo anterior, el espacio urbano de Her remite a la idea del no lugar o espacio del anonimato (Augé, 2008, p. 83), al mostrar a sus habitantes como una población en perpetuo tránsito que casi siempre aparece caminando de prisa por las espectaculares locaciones, en constante interacción con sus dispositivos móviles y aislada del resto de los humanos. Es evidente que la ciudad es una metrópolis, pero podría ser cualquiera y parecería más la representación de una urbe ubicada en un futuro heterotópico, en el que todo tiene lugar y todo puede suceder, hasta la relación amorosa entre un ser humano y un sistema operativo. 
Igualmente compleja resulta la valoración de la función espectacular del paisaje cinematográfico de la ciudad en donde se desarrolla la trama de Her. Si bien la representación del espacio urbano de la película cumple al pie de la letra con la definición original de Higson de servir como "un señuelo visualmente agradable para el ojo del espectador" (1984, p. 3), la revaloración de dicha función como un "vehículo para la relación afectiva entre el espacio y la entidad que lo mira" (Autor/a, 2014, p. 113) no se confirma completamente, al menos en cuanto a que dicha entidad sea alguno de los personajes de la historia.

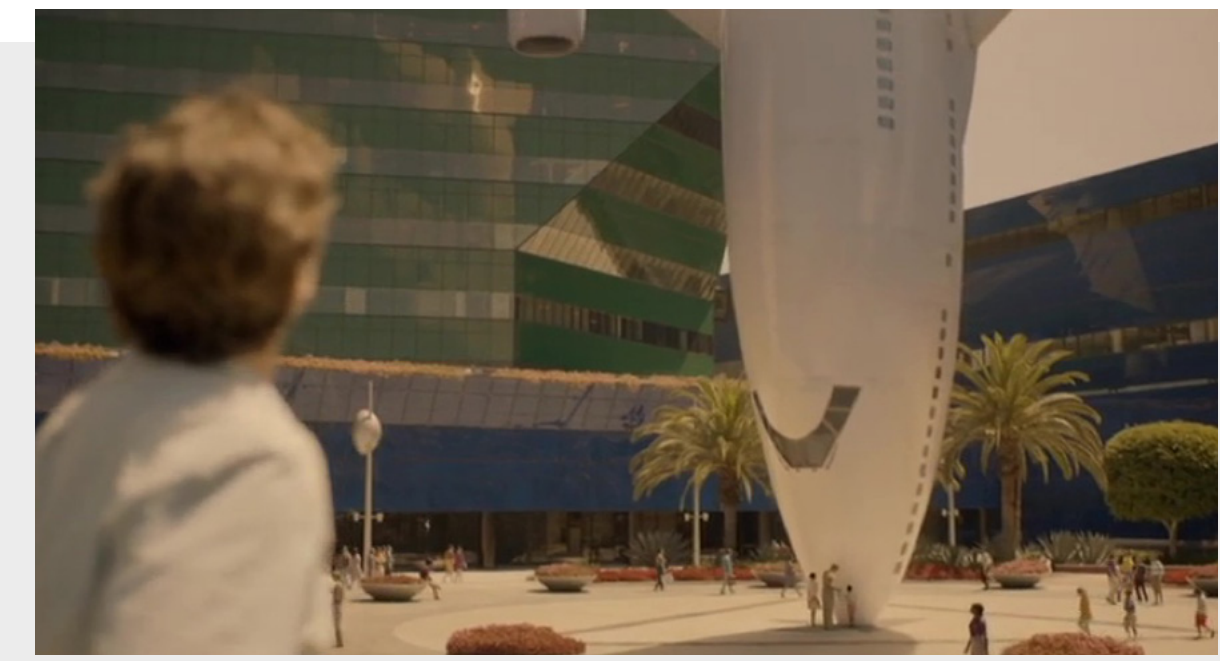

Durante la primera mitad de la película, a lo largo de sus frecuentes paseos por la ciudad, Theodore nunca admira el paisaje que lo rodea. Su intervención en el espacio urbano consiste en caminar en un permanente estado de introspección y en constante interacción con su teléfono inteligente. La primera vez que Theodore dirige la mirada hacia la ciudad sucede cuando han transcurrido 64 minutos desde el comienzo del filme, después de discutir con Samantha por un fallido encuentro sexual con Isabella (Portia Doubleday), una chica que participa en una red de personas que facilitan las relaciones sexuales entre humanos y sistemas operativos. Mientras está sentado sobre la acera, afuera del edificio donde vive, Theodore mira al frente y hacia arriba.

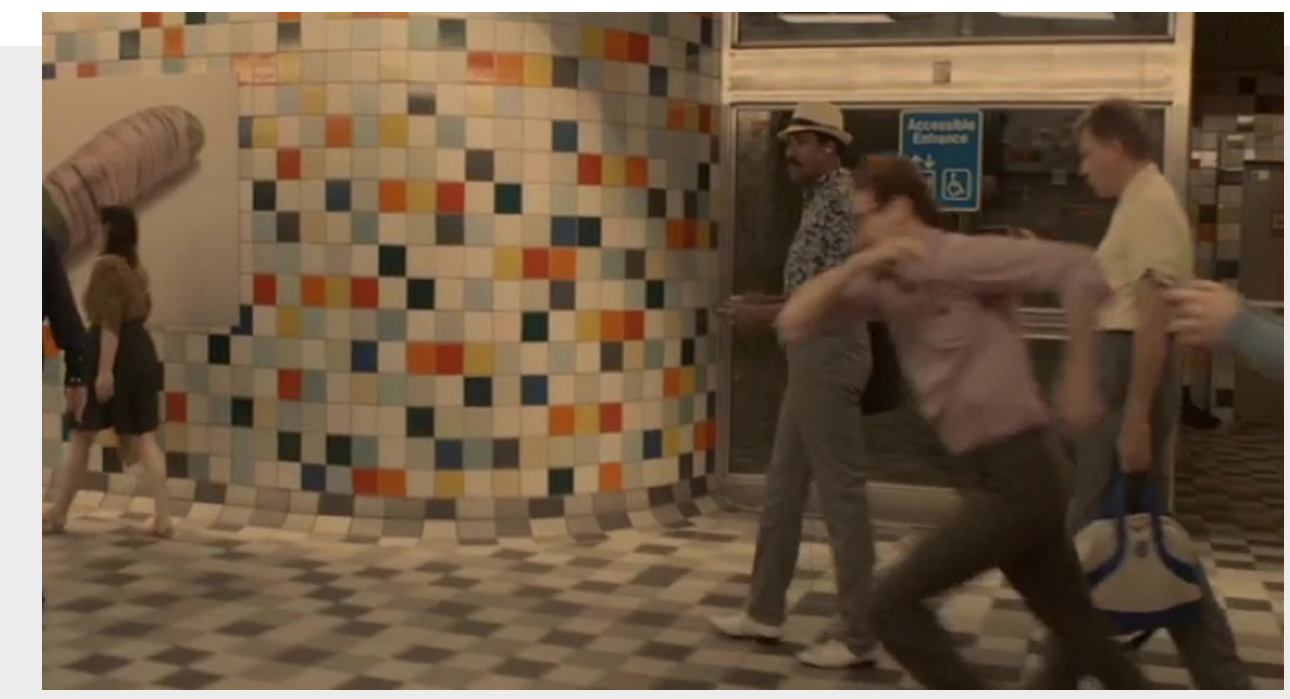


La imagen muestra las enormes figuras de tres rascacielos cuyas siluetas se recortan sobre el cielo nocturno. En la siguiente toma, un abrumado Theodore se deja caer de espaldas sobre el pavimento de la acera. La segunda y última ocasión en que Theodore mira hacia la ciudad ocurre durante el breve interludio que precede al alejamiento de Samantha, entre el minuto 90 y el 92 . La secuencia inicia con Theodore en un parque, sentado junto al dispositivo móvil en el que transporta a Samantha. Ella le comenta que está componiendo una pieza de piano que intenta ser una fotografía de ambos en ese momento de sus vidas.

Mientras suenan los acordes de la melodía, Theodore observa los edificios que rodean al parque, admira el panorama de la ciudad desde el balcón de su departamento y recorre la plaza que se ubica frente al edificio del Pacific Design Center de Los Ángeles, en la que la impresionante escultura de un avión que sostiene todo su peso en la "punta de su nariz" desafía abiertamente la primera ley de Newton. La escasez y brevedad de los momentos que Theodore dedica a mirar a su alrededor parece corroborar que la fría y artificial belleza del paisaje urbano de la película se diseñó como un espectáculo exclusivo para los ojos del espectador.

La segunda locación urbana importante de la película corresponde a los pasillos, el elevador y otros espacios semipúblicos del edificio de departamentos donde habita Theodore. La ambientación de la lujosa torre de departamentos, a la que se accede mediante un elevador decorado con motivos selváticos, la caracteriza como parte de un moderno centro comercial. La presencia de personas que caminan con bolsas de tiendas comerciales acentúa el anonimato del espacio, a la vez público y privado. Los pasillos del edificio se muestran amplios pero un tanto oscuros, en contraste con el exterior del centro comercial, el cual se presenta en colores blanco y marfil. En cierta medida, la función de este espacio como metáfora visual del estado de ánimo del protagonista de Her, se manifiesta a través de la representación de los pasillos oscuros que conducen a su departamento, en un recorrido que reproduce la monotonía en que vive Theodore al inicio de la película.

La tercera ubicación urbana importante de la cinta son las estaciones de metro, la cuales se caracterizan como espacios públicos diseñados para la movilidad y el transporte humanos. Es en una estación donde Theodore descubre el nuevo sistema operativo fabricado por la empresa Elements Software y del cual surge Samantha. Otra estación de metro se convierte en espacio para el juego amoroso entre ambos: camino a la playa, Theodore corre por los pasillos de la estación Hollywood/Western [5] del metro subterráneo de Los Ángeles mientras lleva en el bolsillo de la camisa el dispositivo móvil que "contiene" a Samantha. Tematizada a partir de paredes decoradas con mosaicos de colores primarios, la estación exhibe un aire infantil que, junto con la alegre música folk que se escucha en la escena, contribuye a reforzar la felicidad que expresan Theodore y Samantha.

La última aparición significativa de una estación de metro se presenta hacia el final de la película, después de que Theodore pierde la conexión con Samantha. Theodore corre afuera de su oficina en busca de alguna señal para encontrarla. La acción resulta, hasta cierto punto irónica, puesto que al no existir un lugar físico 
donde pueda localizarla, Theodore confirma su cruel afirmación previa de que, al fin y al cabo, Samantha no es una persona. Theodore pasa de prisa por varios espacios de tránsito, como el elevador y las calles para llegar finalmente a las escaleras de entrada del metro subterráneo donde recupera la conexión. De esta manera, Theodore escenifica su propia versión del mito de Orfeo, al descender a las profundidades del inframundo en busca de su amada.

Mientras baja las escaleras, Theodore observa a la gente que pasa a su lado conversando con sus dispositivos móviles. Al cuestionar a Samantha si en ese momento ella está hablando con alguien más, la respuesta que recibe Theodore es demoledora: son 8,316 personas y sistemas operativos con los que Samantha conversa simultáneamente y 641 de los que está enamorada. El descenso a los infiernos de Theodore es físico y emocional. El metro subterráneo, que en algún momento fue escenario de la felicidad de la pareja, se presenta esta vez como una caverna profunda hacia la que Theodore se precipita. Sentado en los escalones finales de la entrada del metro, Theodore alcanza el punto más bajo de su relación con Samantha. A partir de ese momento, el protagonista de Her debe emprender el camino de regreso hacia su reconexión con el género humano.

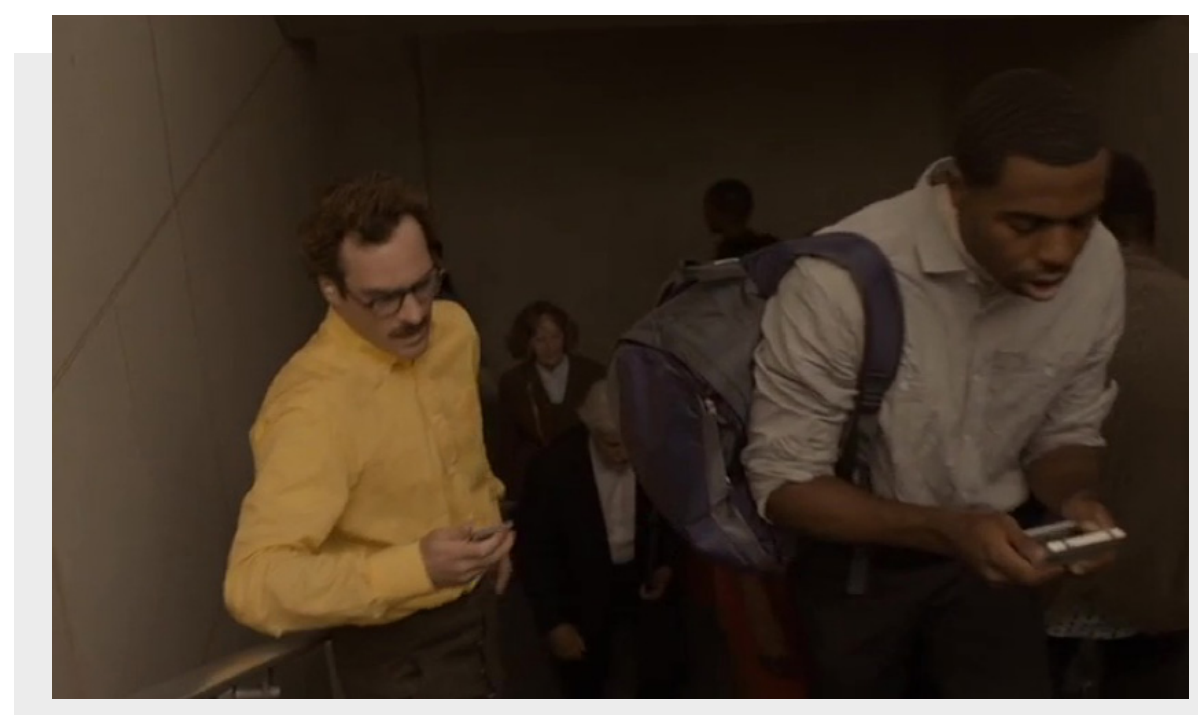

Como conjunto de paisajes cinematográficos, las estaciones de metro de Her cumplen con la función metafórica de representar, en términos espaciales, los altibajos de la relación entre Theodore y Samantha, en una secuencia que va, del encuentro y reconocimiento al enamoramiento y de ahí a la desilusión. Aunque la aspectualización general de las escenas ubicadas en las estaciones de metro no es muy contrastante, la función se cumple por efecto de la macroperación descriptiva de asimilación, o comparación de las características o cualidades particulares de cada espacio. Las diferentes tematizaciones de las estaciones de metro contribuyen a reforzar la metáfora del viaje emocional emprendido por Theodore en su fallido romance con Samantha. 


\section{Conclusiones}

A partir del análisis descriptivo de los elementos de carácter espacial y geográfico más significativos de la película Her del director estadounidense Spike Jonze, es posible concluir que la puesta en escena del filme constituye un importante conjunto de elementos contenedores de información, cuya combinación e integración bajo el concepto de paisaje cinematográfico permite comprender e interpretar la espacialidad de la película y valorarla en términos estéticos e ideológicos.

A partir del análisis descriptivo de los elementos de carácter espacial y geográfico más significativos de la película Her del director estadounidense Spike Jonze, es posible concluir que la puesta en escena del filme constituye un importante conjunto de elementos contenedores de información, cuya combinación e integración bajo el concepto de paisaje cinematográfico permite comprender e interpretar la espacialidad de la película y valorarla en términos estéticos e ideológicos.

La abundancia y variedad de espacios de representación significativos de la cinta permitieron desarrollar un extenso y detallado análisis descriptivo en dos fases: la primera consistió en definir las características del espacio representado en la pantalla; la segunda, en integrar dichas características bajo el concepto de paisaje cinematográfico, analizar sus funciones e interpretar la espacialidad de la película. En lugar de realizar una aproximación cronológica, la presentación de resultados del análisis descriptivo se llevó a cabo en términos espaciales, de acuerdo con la agrupación de los espacios de representación significativos en tres conjuntos, determinados a partir del número de veces que dichos espacios aparecieron en el filme: la oficina y el departamento de Theodore, así como la ciudad y los espacios suburbanos en los que se desarrollan los acontecimientos de la historia.

Con base en lo anterior, una primera conclusión del presente trabajo es haber podido constatar la gran importancia que posee la función metafórica del paisaje cinematográfico en la cinta de Spike Jonze. La mayoría de los espacios analizados cumplen en mayor o menor grado con dicha función, a veces por separado y otras tantas en conjunto con otros espacios. Tanto la oficina como el departamento de Theodore, así como algunas locaciones urbanas, contribuyen a comunicar las distintas etapas de la crisis emocional por la que atraviesa el protagonista del filme.

Así mismo, destaca la manera en que se utilizan las locaciones suburbanas, las cuales funcionan como el gran escenario en el que se desarrollan las etapas principales del romance entre Theodore y Samantha.

Por otra parte, consideramos importante señalar que, aunque la función del paisaje como un espectáculo que atrae la mirada del espectador se manifiesta claramente a lo largo del filme, sobre todo en las escenas ubicadas en los espacios urbanos exteriores, no fue posible establecer una correlación directa entre dicha función y el desarrollo de una relación afectiva entre los personajes de la cinta y el paisaje que los rodea. El espectacular paisaje urbano de la futurista ciudad en que se desarrolla el romance entre Theodore y Samantha pocas veces llama la atención de los protagonistas de Her. 
Más difícil aún fue confirmar la noción de que el paisaje cinematográfico puede cumplir con la función de autentificar la ficción al presentar lugares específicos e históricamente reales. La construcción de una megalópolis a partir de la combinación de imágenes de los espacios urbanos de las ciudades de Los Ángeles y Shanghái, así como la puesta en escena de los espacios interiores más significativos de la película no permiten el total cumplimiento de dicha función del paisaje cinematográfico. En este sentido consideramos que, en la visión del director Spike Jonze, predomina la intención de representar el espacio urbano como una utopía insatisfactoria para sus habitantes, quienes prefieren la falsa seguridad que les proporcionan los espacios virtuales.

Con respecto a este último tipo de espacios de representación significativos, el análisis descriptivo de la película destacó la importancia de las heterotopías o contraemplazamientos de otros espacios, reales o ficticios. Tal es el caso de la oficina de Theodore, un escritorio público, que se contrapone a la noción privada del escritorio como espacio para el trabajo individual. Algunos de los espacios urbanos, como las calles nocturnas y los pasillos oscuros del edificio donde habita el protagonista, cumplen con la función de servir como contraemplazamientos de los espacios idílicos, como la estación del metro, con sus mosaicos de colores de ambiente festivo. Así mismo, el espacio virtual donde se desarrolla la relación sentimental y física entre Theodore y Samantha resulta ser el más importante de todos los espacios representados en la cinta: el más invisible, inmaterial pero profundamente significativo de todos los espacios del universo.

Las anteriores conclusiones confirman el planteamiento realizado en la introducción del presente trabajo, acerca de las posibilidades que ofrecía la cinta para ser estudiada desde la perspectiva espacial de los estudios culturales y desde las aproximaciones y postulados de la geografía cinematográfica. La riqueza de Her de Spike Jonze como texto fílmico es innegable, por lo que seguramente habrá otros estudios que exploren sus cualidades desde diferentes puntos de vista.

\section{Bibliografía}

Adam, J.-M., y Petitjean, A. (1989). Le texte descriptif: poétique historique et linguistique textuelle. París, Francia: Éditions Nathan.

Augé, M. (2008). Los no lugares: espacios del anonimato. Una antropología de la sobremodernidad. Barcelona, España: Gedisa Editorial.

Autor/a (2014).

Barker, C. (2000). Cultural Studies: Theory and Practice. 1a. ed. Londres, Inglaterra: Sage Publications.

Bazin, A. (2005). What Is Cinema? Volume 1. (H. Grey, Trad.) Berkeley, Estados Unidos: University of California Press.

Bordwell, D., Thompson, K. (2003). Arte cinematográfico (Sexta ed.). Ciudad de México, México: McGraw Hill-Interamericana.
Burch, N. (1981). Theory of Film Practice. Princeton, Estados Unidos: Princeton University Press.

Casetti, F., y di Chio, F. (2007). Cómo analizar un film. Barcelona, España: Paidós.

Curbed LA: The Los Angeles Neighborhood and Real Estate Blog (2013, 18 de diciembre). How the Her Filmmakers Created a Utopian Los Angeles of the Not-Too-Distant Future. Curbed LA. Recuperado de: https://la.curbed.com/2013/12/18/1016 6216/how-the-her-filmmakers-created-autopian-los-angeles-of-the

Ellison, M., Landay, V. (Productores) y Jonze, S. (Director) (2013). Her [Película]. Estados Unidos: Sony Pictures Worldwide Acquisitions (SPWA), Annapurna Pictures. 
Escher, A. (2006). The Geography of Cinema - A Cinematic World. Erdkunde, 60(4), 307-314.

Foucault, M. (1999). Espacios diferentes. Estética, ética y hermenéutica. Obras esenciales Volumen III. Barcelona, España: Paidós.

Hawthorne, C. (18 de enero de 2014). Spike Jonze's 'Her': A Refreshingly Original Take on a Future L. A. Los Angeles Times. Recuperado de: http://www.latimes.com/entertainment/ arts/la-et-cm-her-architecture-notebookstory.html\#page $=1$.

Higson, A. (1984). Space, Place, Spectacle: Landscape and Townscape in the 'Kitchen Sink' Film. Screen: Incorporating Screen Education, 25, 2-21.

-. (1987). The Landscapes of Television Landscape Research, 12(3), 8-13.

Jackson, P. (1999). ¿Nuevas geografías culturales? Documents d'analisi geografica (34), 41-51.

Jonze, S. (2011). Her. Guión cinematográfico (sin publicar).
Kracauer, S. (1997). Theory of Film: The

Redemption of Physical Reality.

Princeton, Estados Unidos: Princeton University Press.

Lefebvre, H. (1991). The Production of Space. Malden, Estados Unidos: Blackwell Publishing.

Lukinbeal, C. (2005). Cinematic Landscapes. Journal of Cultural Geography, 23 (1), 3-22.

Miéville, D. (1986). Prélude à l'analyse de la description. Travaux du Centre de Recherches Sémiologiques, 15, 119-146. Recuperado de: http://doc.rero.ch/record/260927/files/ Mi_ville_Denis_-_Pr_lude_I_analyse_de_I a_description_20160616.pdf

Soja, E. W. (1994). Postmodern Geographies: The Reassertion of Space in Critical Social Theory. Londres, Inglaterra: Verso.

Vardac, A. N. (2007). Stage to Screen Theatrical Method from Garrick to Grifith. La Mirada, Estados Unidos: Davidson Press.

Vale, E. (2006). Técnicas del guion para cine y televisión. Ciudad de México, México: Gedisa Editorial.

\section{Notas}

[1] Título original: Ella (Her, 2013). País: Estados Unidos. Año: 2013. Dirección: Spike Jonze. Guión: Spike Jonze. Reparto: Joaquin Phoenix, Amy Adams, Scarlett Johansson. Género: Ciencia ficción, Drama, Comedia

[2] Vale (2006) distingue a los objetos de los accesorios en cuanto a que los primeros poseen capacidad de "actuar" en la escena.

[3] Traducción propia.
[4] A este respecto, resulta importante destacar la actuación de la actriz Scarlett Johansson como Samantha, quien logra la difícil tarea de singularizar al personaje únicamente a partir de su interpretación vocal.

[5] Traducción propia.

[6] Lugar donde fue filmada la escena pero que no es mencionado explícitamente en la película.

Para citar este artículo:

Maza Pérez, Maximiliano y Godínez Garza, Frida Anais (2019). PAISAJES CINEMATOGRÁFICOS COMO METÁFORAS DE LAS EMOCIONES. Análisis de los modos de representación fílmica y espacialidad en Her de Spike Jonze. Revista Luciérnaga Comunicación. Vol. 11, Núm. 21. Pp 40 - 59. DOI: https://doi.org/10.33571/revistaluciernaga.v11n21a2 